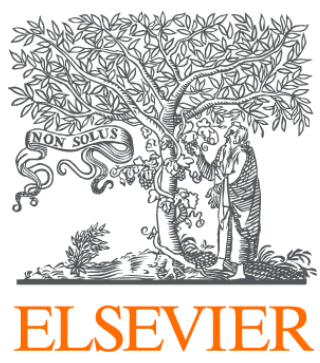

Since January 2020 Elsevier has created a COVID-19 resource centre with free information in English and Mandarin on the novel coronavirus COVID-

19. The COVID-19 resource centre is hosted on Elsevier Connect, the company's public news and information website.

Elsevier hereby grants permission to make all its COVID-19-related research that is available on the COVID-19 resource centre - including this research content - immediately available in PubMed Central and other publicly funded repositories, such as the WHO COVID database with rights for unrestricted research re-use and analyses in any form or by any means with acknowledgement of the original source. These permissions are granted for free by Elsevier for as long as the COVID-19 resource centre remains active. 


\title{
Big Five predictors of pandemic-related behavior and emotions in the first and second COVID-19 pandemic wave in Slovakia
}

\author{
Michal Kohút *, Veronika Kohútová, Peter Halama \\ Faculty of Philosophy and Arts, University of Trnava, Hornopotočná 23, 91843 Trnava, Slovakia
}

\section{A R T I C L E I N F O}

\section{Keywords:}

COVID-19

Pandemic

Personality

Big Five

\begin{abstract}
A B S T R A C T
This study explores the effect of Big Five personality traits on behavioral and emotional responses to the COVID19 pandemic. Personality traits of 248 Slovak persons were assessed twice before the pandemic using the Big Five Inventory 2. Behavioral and emotional responses to the pandemic were collected during the first and second pandemic wave (April and September 2020). The results showed a statistically significant decrease in all response domains and in COVID-19 fear between the first and the second pandemic wave, suggesting that psychological adaptation to the pandemic occurred during the interim period. The results identified several meaningful links between the traits and pandemic-related behavior and emotions, especially for neuroticism, extraversion, and conscientiousness. However, the effects of personality were higher for the first pandemic wave, suggesting that these effects vary across time probably because of changes in pandemic perception in the society.
\end{abstract}

\section{Introduction}

The new worldwide situation concerning COVID-19 disease changed the daily life of people all over the world. Disease outbreaks in general evoke various psychological responses. Some of them directly follow government recommendations, e.g. handwashing, mask-wearing, or social distancing as in the case of the COVID-19 pandemic (www. korona.gov.sk/en/). Other behavioral responses arise as a reaction to the unknown threatening situation, including overbuying and stockpiling (e.g. Badgaiyan \& Verma, 2015), searching for information (e.g. Jang \& Baek, 2019) or helping others (e.g. Smith et al., 2009). Responses also relate to emotional reactions to a crisis such as fear, anger, boredom due to the quarantine (e.g. Brooks et al., 2020), or behavior that mitigates the negative emotional reactions, for instance self-distraction or engaging in activities to improve one's mood like relaxing, art (e.g. Diefendorff et al., 2008), praying, etc. (e.g. Bentzen, 2019).

Several studies showed that the pandemic responses might be related to personality traits. People higher in conscientiousness and agreeableness showed higher compliance with guidelines (Bogg \& Milad, 2020; Zajenkowski et al., 2020) as well as handwashing (Blagov, 2020; Carvalho et al., 2020; Shook et al., 2020). Social distancing during pandemic was higher in people with high conscientiousness, openness to experience, agreeableness, and low extraversion (Blagov, 2020; Carvalho et al., 2020; Chan et al., 2020). Greater stockpiling was predicted by higher extraversion and neuroticism and lower conscientiousness and openness (Dammeyer, 2020; Garbe et al., 2020). Prosocial behavior such as helping or donating was found to be positively connected to agreeableness (Habashi et al., 2016), which was confirmed by a meta-analysis which, in addition, found the importance of openness for experience for such behavior (Kline et al., 2019). The negative emotional response to COVID-19 as worries, negative repetitive thoughts or boredom were affected by neuroticism (Caci et al., 2020; Kroencke et al., 2020).

Many of these relationships are consistent with the patterns of associations between personality and disease avoidance, which includes perceived infectability and germ avoidance (Duncan et al., 2009). Duncan et al. (2009) showed that perceived infectability correlated weakly with high neuroticism, low agreeableness and conscientiousness, and germ aversion with high neuroticism, low openness, agreeableness, and extraversion. Oosterhoff et al. (2018) made a meta-analysis, which showed that personality correlates of disease avoidance were high neuroticism, high conscientiousness, low extraversion, and low openness. They attributed their results the to the activity of the Behavioral Immune System (Schaller, 2006), which detects and responds to potential sources of contamination. Oosterhoff et al. (2018) emphasized, that specific traits can be more or less conducive to its activity. This suggests that links between personality traits and COVID-19 responses may be mediated by general disease avoidance.

\footnotetext{
* Corresponding author.

E-mail addresses: michal.kohut@truni.sk (M. Kohút), peter.halama@truni.sk (P. Halama).
} 


\subsection{Current study}

The basic aim of this study is to explore how Big Five personality traits measured before pandemic of COVID-19 predict the behavioral and emotional responses to it. The current study contributes to previous ones by using a longitudinal design and focusing on 2 different waves of pandemic in Slovakia. It is based on previous research and assumption, that some of the traits can stimulate the expression of disease avoidance behavior, which is applied to COVID-19 as well.

The COVID-19 pandemic is a long-lasting life-threatening situation, which may provoke various strong reactions. However, peoples' responses might change in time due to adaptation to major negative life events (Infurna \& Luthar, 2018). In our study, we focus on the question whether personality traits affect the response to pandemic differently in the first COVID-19 wave (April 2020) and the second one (September 2020). We assume that these situations are different because adaptation to a pandemic happened during the interim period. To confirm this in our study, we also explore the differences in behavioral and emotional responses between these time points. Moreover, we decided to include the measure of COVID-19 fear as control variable of adaptation, which we assumed to be lower in the second wave compared to the first wave. Finally, we decided to explore whether this change in the responses is predicted by personality traits.

\section{Method}

\subsection{Sample}

The sample used in this study builds on the longitudinal sample used in Kohút et al. (2020), to which we added two rounds of data collection. Altogether, four rounds were done using an online panel. Participants were recruited by a research agency, agreed-upon informed consent, and were compensated for their participation. Preliminary analysis was done using data from the third round on 280 participants (57.1\% men) who were between 19 and 75 years old $(M=47.20, S D=14.29)$. The final sample consists of 248 participants, 142 (57.3\%) men and 106 (42.7\%) women, who passed the attention-check items and completed each round. These participants were between 19 and 75 years old $(M=48.00$, $\mathrm{SD}=14.30), \mathrm{M}=46.40(\mathrm{SD}=14.30)$ for men and $\mathrm{M}=50.20$ ( $\mathrm{SD}=$ 14.10) women.

\subsection{Measures}

The Slovak Big Five Inventory-2 (BFI-2; Halama et al., 2020, Soto \& John, 2017) contains 60 items focused on measuring five broad personality traits - Extraversion, Agreeableness, Conscientiousness, Negative Emotionality, and Open-Mindedness. This inventory was used in the first two rounds of data collection. In the current study, we averaged each item score from the first and second round and calculated composite domain scores. Cronbach's alpha ranged from 0.83 for Extraversion domain to 0.90 for Negative emotionality domain, suggesting strong internal consistency of composite domain scores.

To assess the fear of COVID-19 in the first and the second pandemic wave, we used the newly developed Fear of COVID-19 scale (Ahorsu et al., 2020). This inventory is focused on assessing the fear of COVID-19 infection. In our study, we used the full 10 items version. Participants indicate the agreement or disagreement with these statements using 5point scales. Cronbach's alpha was 0.91 in both waves.

Behavioral and emotional responses connected to the COVID-19 pandemic situation were assessed by 37 self-constructed items about various behavioral acts, activities, or emotions in the last 2 weeks. The items were created to cover the most relevant behavioral and emotional manifestations related to COVID-19, such as following recommendations, interpersonal behavior, emotional response, etc. These items shared the same stem "For the last 2 weeks..." and continued with various statements, e.g. "I was disinfecting my personal stuff".
Participants indicated their involvement in these activities using 5-point scales: "Never", "Rarely", "Occasionally", "Often" and "Every time". These options were explained in more detail in the introduction of the questionnaire. These items were used for the third round of data collection. Only 29 items were retained after the preliminary exploratory factor analysis in the last round of data collection.

\subsection{Analysis}

In the first step, we did a preliminary analysis of items mapping behavioral and emotional responses to the pandemic. The correlation matrix showed high correlations between the items (some reaching the level of 0.6-0.7), suggesting substantial shared variance between the items. Due to this reason, we decided to reduce the number of variables measuring behavioral and emotional responses through exploratory factor analysis (EFA). As we expected the factors to correlate, principal axis factoring extraction with oblimin rotation was used. One item had unsatisfactory value in the Kaiser-Meyer-Olkin (KMO) measure of sampling adequacy $(<0.5)$, therefore, we reran the analysis without this item. Following the EFA results, we then focused on the meaning of these factors and adjusted the final set of items to be used in the final data collection. Twenty-nine items were used in the final round of data collection. Based on the content of items in each factor, we named them "Active protection, following recommendations", "Stockpiling and purchasing", "Relaxation and emotional improvement", "Negative emotional response", "Search for information" and "Helping others" domains. The factor loadings and items' assigned domain are presented in Appendix in Table A.

To verify the factor structure from the preliminary EFA analysis, we conducted confirmatory factor analysis (CFA) using robust maximum likelihood estimator and correlated factors. We then computed the internal consistency of each domain, using Cronbach's alpha. To assess the change of these domains in time, we computed difference variables by subtracting the second pandemic wave domain score from the first pandemic wave domain score. Then we focused on assessing the difference of the COVID-19 domains and the fear of COVID-19. For this, we used the paired samples $t$-test. Subsequently, we assessed the effect of the Big Five personality domains on the COVID-19 behavior domains using multiple hierarchical linear regression analyses. In these, we set each of the COVID-19 behavioral and emotional domains separately as the outcome variable. In the first step, gender and age was used as predictors. In the second step we added BFI-2 domains. These analyses were computed separately for the first and the second pandemic wave. To assess how personality predicts the change of COVID-19 domains, we used the change score as outcome.

\section{Results and discussion}

\subsection{CFA of COVID-19 behavioral and emotional responses}

The results of CFA with items focused on behavioral and emotional response to pandemic showed acceptable model fit $(\mathrm{CFI}=0.88$, TLI $=$ 0.87 , RMSEA $=0.06,95 \%$ CI $[0.05,0.07]$, SRMR $=0.07$ ). Detailed results of CFA are presented in Table B in the Appendix. The latent factor correlations, as well as Cronbach's alpha for COVID-19 domains and correlations between manifest domain scores in both pandemic waves are presented in Table $\mathrm{C}$ in the Appendix.

\subsection{Comparison between the two COVID-19 pandemic waves}

Table 1 reports the results of $t$-tests of the COVID-19 domains and fear of COVID-19 between the two pandemic waves. There was a significant decrease for fear of COVID-19 and all COVID-19 domains, with the largest differences for active protection and following rules and purchasing and stockpiling. These results confirmed the assumed changes between two pandemic waves attributed to adaptation to major 
Table 1

Paired samples $t$-test of COVID-19 domains and fear of COVID-19.

\begin{tabular}{|c|c|c|c|c|c|c|c|c|c|}
\hline \multirow[b]{2}{*}{ Domain } & \multicolumn{2}{|c|}{ First wave } & \multicolumn{2}{|c|}{ Second wave } & \multicolumn{4}{|c|}{ Paired t-test } & \multirow[t]{2}{*}{ Pearson's $r$} \\
\hline & Mean & SD & Mean & SD & $\mathrm{t}$ & $\mathrm{df}$ & Cohen's d & $95 \%$ CI & \\
\hline APFR & 3.77 & 0.60 & 3.27 & 0.78 & 13.15 & 247 & 0.84 & {$[0.69 ; 0.98]$} & 0.67 \\
\hline PS & 2.38 & 0.95 & 2.05 & 0.97 & 6.43 & 247 & 0.41 & {$[0.28 ; 0.54]$} & 0.64 \\
\hline REI & 3.05 & 0.69 & 2.86 & 0.78 & 4.04 & 247 & 0.26 & {$[0.13 ; 0.38]$} & 0.54 \\
\hline NER & 2.52 & 0.79 & 2.35 & 0.73 & 3.78 & 247 & 0.24 & {$[0.11 ; 0.37]$} & 0.58 \\
\hline SFI & 3.11 & 0.90 & 2.75 & 1.02 & 6.07 & 247 & 0.39 & {$[0.26 ; 0.51]$} & 0.52 \\
\hline $\mathrm{HO}$ & 1.97 & 0.77 & 1.78 & 0.74 & 3.60 & 247 & 0.23 & {$[0.10 ; 0.35]$} & 0.37 \\
\hline FOC & 2.60 & 0.84 & 2.21 & 0.77 & 9.07 & 247 & 0.58 & {$[0.44 ; 0.71]$} & 0.64 \\
\hline
\end{tabular}

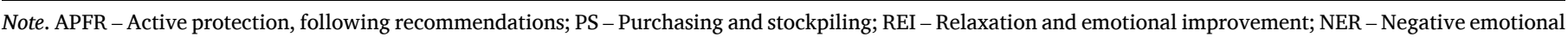
response; SFI - Search for information; HO - Helping others; FOC - Fear of COVID-19. All differences are significant at $\mathrm{p}<0.01$.

negative life events (Infurna \& Luthar, 2018). The recent results from other countries confirmed that this adaptation happens all around the world, e.g. in the US, where psychological distress, after rapid increase in March 2020, significantly decreased in April and achieved almost prepandemic level by June 2020, although the number of cases and deaths rose (Daly \& Robinson, 2020). The study of Sadiković et al. (2020) found similar results for Serbia, where the level of negative emotions decreased during the 5 weeks of the pandemic period, even though the number of deaths increased. In Slovakia, the first wave occurred in the spring of 2020, when state restrictions were strong, but the number of cases and deaths were relatively low (e.g. circa 700 active infected cases in the second week of April 2020). Although the number of infected people in September 2020 was higher than in the first wave (circa 2100 active infected cases in the second week of September 2020), only weak restrictions were imposed by the government and people were less cautious even though concerns started to rise. The idea of adaptation between the first and the second wave is also supported by sociological data showing that the percentage of people feeling fear of COVID-19 weakened from $32.7 \%$ in April to $27.2 \%$ in September. Moreover, the decrease was found for social distancing as well (in April, $46 \%$ of respondents limited social contacts compared to just $12.2 \%$ in September) and increase for feeling no danger concerning COVID-19 (from 21\% in April to $25.8 \%$ in September) (Slovensko, 2020).

\subsection{Effect of Big Five traits on COVID-19 domains}

To explore the effect of personality traits on COVID-19 domains controlled for gender and age, we carried out multiple hierarchical linear regression analysis, the results of which we report in Table 2. Full correlation matrix for variables used in these analyses is presented in the Appendix (Table D). The results showed several meaningful predictive effects of personality traits. For the first wave, extraversion predicted positively purchasing and stockpiling as well as negative emotional response. Although the effect of extraversion on negative emotional response can be surprising and inconsistent with the results on personality correlates of general disease avoidance (Oosterhoff et al., 2018), we believe that extraversion, which can increase reliance on interpersonal sources of information (Mooradian \& Swan, 2006), can facilitate the feelings of threats especially when this is the dominant emotion shared in the society. We expect similar mechanism behind the effect of extraversion on purchasing and stockpiling, which is supported by the fact that another predictor of such behavior is negative emotionality. Based on this, purchasing and stockpiling seems to be a compulsive activity activated by feelings of threats mediated by other people. The negative emotionality predicted two other kinds of response: negative emotions and search for information. Both these effects are in line with other studies (eg. Caci et al., 2020) and the assumed activity of the Behavioral Immune System (Oosterhoff et al., 2018). Our data suggests that also search for information during the pandemic can be stimulated by feelings of anxiety or disgust and can be attributed to the general disease avoidance.

A contradictory effect in the first wave was found for conscientiousness. Based on previous research (Bogg \& Milad, 2020; Zajenkowski et al., 2020), we assumed a positive relationship with active protection and following recommendation, however, this effect was not confirmed. Instead, conscientiousness was found to predict purchasing and stockpiling (positively) and relaxation and emotional improvement (negatively). As conscientious people are goal oriented and have higher consideration for future consequences (Cao \& Xia, 2020), we assume that this mechanism of conscientiousness can play a role in both increasing purchasing and stockpiling (to avoid shortage of important things in the future) and decreasing relaxation and emotional improvement, as this one deals more with the current state than with future consequences. However, relaxation and emotional improvement was predicted positively by open-mindedness. The analysis of the items in this factor shows, that it includes the effort to find new ways of overcoming limitations caused by the pandemic, and open-mindedness can increase this activity. Finally, helping others in the first wave was predicted by agreeableness, which again is a predictable result, as prosocial behavior such as helping or donating is frequently associated with agreeableness (Habashi et al., 2016; Kline et al., 2019).

However, most of these effects diminished in the second wave. Our results clearly show that the effect of personality traits was lower in the second wave than in the first wave. This is also evident from the comparison of the explained variance by full models (Table 2). In the first wave, the average explained variance across all COVID-19 domains was $12.08 \%$, for the second wave, it was only $5.67 \%$. More specifically, the average amount of variance added by personality traits was $9.11 \%$ for the first wave and only $6.18 \%$ for the second wave.

Concerning the change in behavioral and emotional response to the pandemic, the analysis showed almost no predictive effect of personality traits. The percentages of variance explained by the models were low across all domains (ranging from $2,3 \%$ to 5,5\%). Only extraversion positively predicted a decrease in purchasing and stockpiling and agreeableness positively predicted a decrease in helping others, however, both of these effects could be attributed to the fact, that these traits substantially predicted these behaviors in the first wave, but the effects diminished together with the decrease of these behaviors in the second wave. Significant regression coefficients in these cases are rather statistical artefacts coming from the differences between the effects in both waves than personality driven changes.

To explain the different effect of personality in two pandemic waves, we need to understand the differences in the overall situation perceptions of these two time points. The first weeks and months of pandemic brought substantial changes in people's lives together with unknown threats. Feeling of lack of control over the pandemic, which is associated with increased level of disinformation and conspiracy theories (Šrol et al., 2021), can increase the level of perceived threats and this perception has the potential to elicit some personality expressions (Bedford-Petersen \& Saucier, 2021). On the other hand, in the second pandemic wave people got used to restrictions and changes in daily lives (Levkovich \& Shinan-Altman, 2020) and their anxiety decreased. According to Zajenkowski et al. (2020), a perception of the situation might be a more important source of COVID-19 related behavior than 
Table 2

Results of linear regression analysis predicting COVID-19 domains.

\begin{tabular}{|c|c|c|c|c|c|c|}
\hline \multirow[b]{2}{*}{ Predictor } & \multicolumn{2}{|c|}{ First wave of COVID-19 } & \multicolumn{2}{|c|}{ Second wave of COVID-19 } & \multicolumn{2}{|c|}{ Difference } \\
\hline & $\beta$ & $95 \% \mathrm{CI}$ & $\beta$ & $95 \% \mathrm{CI}$ & $\beta$ & $95 \% \mathrm{CI}$ \\
\hline \multicolumn{7}{|c|}{ Active protection, following recommendations } \\
\hline & \multicolumn{2}{|c|}{$R^{2}=0.115, \Delta \mathrm{R}^{2}=0.041$} & \multicolumn{2}{|c|}{$R^{2}=0.087, \Delta \mathrm{R}^{2}=0.026$} & \multicolumn{2}{|c|}{$\mathrm{R}^{2}=0.029, \Delta \mathrm{R}^{2}=0.017$} \\
\hline Gender & 0.43 & {$[0.16,0.70]$} & 0.36 & {$[0.08,0.63]$} & -0.03 & {$[-0.31,0.25]$} \\
\hline Age & 0.00 & {$[-0.12,0.12]$} & 0.09 & {$[-0.04,0.21]$} & -0.11 & {$[-0.24,0.01]$} \\
\hline Extraversion & 0.08 & {$[-0.07,0.24]$} & -0.03 & {$[-0.18,0.13]$} & 0.12 & {$[-0.04,0.28]$} \\
\hline Agreeableness & 0.11 & {$[-0.04,0.26]$} & 0.05 & {$[-0.11,0.20]$} & 0.05 & {$[-0.11,0.21]$} \\
\hline Conscientiousness & 0.11 & {$[-0.03,0.26]$} & 0.12 & {$[-0.03,0.27]$} & -0.04 & {$[-0.19,0.11]$} \\
\hline Negative emotionality & 0.11 & {$[-0.05,0.27]$} & 0.11 & {$[-0.05,0.27]$} & -0.04 & {$[-0.20,0.13]$} \\
\hline Open-mindedness & 0.03 & {$[-0.12,0.18]$} & 0.08 & {$[-0.07,0.23]$} & -0.07 & {$[-0.23,0.08]$} \\
\hline \multicolumn{7}{|c|}{ Purchasing and stockpiling } \\
\hline & \multicolumn{2}{|c|}{$R^{2}=0.114, \Delta R^{2}=0.086$} & \multicolumn{2}{|c|}{$R^{2}=0.094, \Delta R^{2}=0.044$} & \multicolumn{2}{|c|}{$\mathrm{R}^{2}=0.038, \Delta \mathrm{R}^{2}=0.030$} \\
\hline Gender & 0.20 & {$[-0.07,0.47]$} & 0.35 & {$[0.08,0.62]$} & -0.18 & {$[-0.46,0.10]$} \\
\hline Age & -0.02 & {$[-0.15,0.10]$} & 0.03 & {$[-0.10,0.15]$} & -0.06 & {$[-0.19,0.07]$} \\
\hline Extraversion & 0.27 & {$[0.12,0.43]$} & 0.11 & {$[-0.04,0.27]$} & 0.18 & {$[0.02,0.35]$} \\
\hline Agreeableness & 0.03 & {$[-0.12,0.18]$} & -0.01 & {$[-0.16,0.15]$} & 0.05 & {$[-0.11,0.20]$} \\
\hline Conscientiousness & 0.17 & {$[0.02,0.31]$} & 0.12 & {$[-0.03,0.26]$} & 0.06 & {$[-0.09,0.21]$} \\
\hline Negative emotionality & 0.28 & {$[0.12,0.44]$} & 0.24 & {$[0.08,0.39]$} & 0.05 & {$[-0.12,0.21]$} \\
\hline Open-mindedness & -0.20 & {$[-0.35,-0.05]$} & -0.10 & {$[-0.25,0.05]$} & -0.11 & {$[-0.27,0.04]$} \\
\hline \multicolumn{7}{|c|}{ Relaxation and emotional improvement } \\
\hline & \multicolumn{2}{|c|}{$R^{2}=0.152, \Delta R^{2}=0.108$} & \multicolumn{2}{|c|}{$R^{2}=0.122, \Delta R^{2}=0.074$} & \multicolumn{2}{|c|}{$\mathrm{R}^{2}=0.033, \Delta \mathrm{R}^{2}=0.021$} \\
\hline Gender & 0.33 & {$[0.07,0.59]$} & 0.23 & {$[-0.03,0.50]$} & 0.07 & {$[-0.22,0.35]$} \\
\hline Age & 0.02 & {$[-0.10,0.14]$} & 0.14 & {$[0.02,0.26]$} & -0.13 & {$[-0.26,0.00]$} \\
\hline Extraversion & 0.05 & {$[-0.10,0.20]$} & 0.02 & {$[-0.14,0.17]$} & 0.03 & {$[-0.13,0.19]$} \\
\hline Agreeableness & 0.15 & {$[0.00,0.29]$} & 0.05 & {$[-0.10,0.20]$} & 0.09 & {$[-0.07,0.25]$} \\
\hline Conscientiousness & -0.15 & {$[-0.29,-0.01]$} & -0.08 & {$[-0.23,0.06]$} & -0.05 & {$[-0.20,0.10]$} \\
\hline Negative emotionality & 0.07 & {$[-0.09,0.22]$} & 0.14 & {$[-0.02,0.30]$} & -0.09 & {$[-0.25,0.07]$} \\
\hline Open-mindedness & 0.29 & {$[0.14,0.43]$} & 0.28 & {$[0.13,0.42]$} & -0.02 & {$[-0.18,0.13]$} \\
\hline \multicolumn{7}{|c|}{ Negative emotional response } \\
\hline & \multicolumn{2}{|c|}{$R^{2}=0.188, \Delta R^{2}=0.183$} & $R^{2}=0$ & .147 & $\mathrm{R}^{2}=0$ & 0.017 \\
\hline Gender & 0.01 & {$[-0.25,0.27]$} & 0.09 & {$[-0.17,0.35]$} & -0.09 & {$[-0.37,0.20]$} \\
\hline Age & 0.01 & {$[-0.11,0.13]$} & 0.11 & {$[-0.01,0.23]$} & -0.11 & {$[-0.24,0.02]$} \\
\hline Extraversion & 0.18 & {$[0.03,0.33]$} & 0.09 & {$[-0.06,0.24]$} & 0.10 & {$[-0.06,0.27]$} \\
\hline Agreeableness & -0.04 & {$[-0.19,0.10]$} & -0.12 & {$[-0.27,0.03]$} & 0.08 & {$[-0.08,0.23]$} \\
\hline Conscientiousness & -0.09 & {$[-0.23,0.05]$} & -0.02 & {$[-0.16,0.12]$} & -0.08 & {$[-0.23,0.07]$} \\
\hline Negative emotionality & 0.42 & {$[0.27,0.57]$} & 0.35 & {$[0.20,0.50]$} & 0.11 & {$[-0.05,0.28]$} \\
\hline Open-mindedness & -0.05 & {$[-0.19,0.10]$} & -0.01 & {$[-0.16,0.13]$} & -0.04 & {$[-0.20,0.12]$} \\
\hline Search for information & & & & & & \\
\hline & $\mathrm{R}^{2}=0$ & .050 & $R^{2}=0$ & 0.039 & $\mathrm{R}^{2}=0$ & 0.013 \\
\hline Gender & -0.04 & {$[-0.31,0.24]$} & 0.07 & {$[-0.21,0.34]$} & -0.11 & {$[-0.39,0.17]$} \\
\hline Age & 0.01 & {$[-0.12,0.14]$} & 0.09 & {$[-0.03,0.22]$} & -0.09 & {$[-0.22,0.04]$} \\
\hline Extraversion & 0.02 & {$[-0.14,0.18]$} & -0.09 & {$[-0.25,0.07]$} & 0.12 & {$[-0.04,0.28]$} \\
\hline Agreeableness & 0.13 & {$[-0.03,0.28]$} & 0.07 & {$[-0.09,0.23]$} & 0.05 & {$[-0.11,0.21]$} \\
\hline Conscientiousness & 0.11 & {$[-0.03,0.26]$} & 0.13 & {$[-0.02,0.28]$} & -0.03 & {$[-0.18,0.12]$} \\
\hline Negative emotionality & 0.21 & {$[0.05,0.37]$} & 0.16 & {$[0.00,0.32]$} & 0.03 & {$[-0.14,0.19]$} \\
\hline Open-mindedness & 0.08 & {$[-0.07,0.24]$} & 0.07 & {$[-0.08,0.23]$} & 0.00 & {$[-0.16,0.16]$} \\
\hline Helping others & & & & & & \\
\hline & $R^{2}=0$ & .079 & $\mathrm{R}^{2}=0$ & 0.041 & $\mathrm{R}^{2}=0$ & 0.038 \\
\hline Gender & 0.15 & {$[-0.12,0.42]$} & 0.08 & {$[-0.20,0.36]$} & 0.07 & {$[-0.21,0.35]$} \\
\hline Age & -0.11 & {$[-0.24,0.01]$} & 0.04 & {$[-0.08,0.17]$} & -0.14 & {$[-0.27,-0.02]$} \\
\hline Extraversion & 0.15 & {$[-0.01,0.30]$} & 0.09 & {$[-0.07,0.25]$} & 0.05 & {$[-0.11,0.21]$} \\
\hline Agreeableness & 0.19 & {$[0.04,0.34]$} & 0.01 & {$[-0.15,0.16]$} & 0.17 & {$[0.01,0.32]$} \\
\hline Conscientiousness & 0.07 & {$[-0.07,0.22]$} & 0.01 & {$[-0.14,0.16]$} & 0.06 & {$[-0.09,0.21]$} \\
\hline Negative emotionality & 0.09 & {$[-0.07,0.25]$} & 0.12 & {$[-0.05,0.28]$} & -0.02 & {$[-0.18,0.14]$} \\
\hline Open-mindedness & 0.03 & {$[-0.12,0.18]$} & 0.16 & {$[0.00,0.31]$} & -0.11 & {$[-0.27,0.04]$} \\
\hline
\end{tabular}

Note. CI - Confidence interval; $\mathrm{R}^{2}$ - values for full model; $\Delta \mathrm{R}^{2}$ - unique variance explained by BFI- 2 domains. Values significant at $\mathrm{p}<0.05$ are italicized. Gender: men were coded as 1 and women as 2 .

personality traits. The results of our study suggest that situation perception can interact with personality traits in prediction of behavior, specifically, a situation perceived as more threating can evoke responses driven by personality traits.

\subsection{Limitations and future directions}

This study has some important limitations that need to be mentioned. Firstly, our research was exploratory, and we did not set specific hypothesis. This was caused mainly by the lack of sources at the time of the planning and by the lack of time to start the data collection. Secondly, the method used for behavior measurement was self-report, which may be biased by social desirability and the fact that respondents gave only one evaluation each time. Using daily behavior reports would be more appropriate, to better reflect their behavior. In the context of the method used, the items were created by brainstorming, trying to focus on behavior connected to a pandemic situation without targeting any adhoc specific domains. The domains used were created post-hoc, using exploratory factor analysis. Furthermore, in our design we did not include other important variables such as subjective evaluation of the current situation. Finally, our findings are limited by the low number of participants. Although, a longitudinal sample was used, its size does not 
necessarily fully represent the whole Slovak population.

Our study confirmed several meaningful links between Big Five personality traits assessed before pandemic of COVID-19 and behavioral and emotional response during the pandemic. Some of these relationships (e.g. for neuroticism) corresponded with the pattern of associations between personality traits and general disease avoidance (Oosterhoff et al., 2018), some of them (e.g. for extraversion) suggested that other mechanisms can be involved. However, we found that these effects vary across time, probably because of psychological adaptation to the pandemic, which occurs along with its duration. Our study is the first which pointed to this variation using a longitudinal design. Our findings suggested that when studying personality traits as predictors of behavior in a pandemic or a similar situation, one needs to consider specific characteristics of a concrete situation (e.g., actual perception of threats in the society). Future research should focus on controlling for these specific situation characteristics and exploring the mechanisms of their interaction with personality traits.

\section{CRediT authorship contribution statement}

Michal Kohút: Conceptualization, Methodology, Formal analysis, Investigation, Data curation, Writing - original draft, Funding acquisition. Veronika Kohútová: Conceptualization, Resources, Writing original draft, Writing - review \& editing. Peter Halama: Conceptualization, Methodology, Resources, Writing - original draft, Writing review \& editing, Supervision, Funding acquisition.

\section{Acknowledgements}

This work was supported by the Scientific Grant Agency VEGA [grant number 1/0363/18].

\section{Appendix A}

Table A

Results of EFA of COVID-19 related behavior items from the first pandemic wave.

\begin{tabular}{|c|c|c|c|c|c|c|c|}
\hline Final domain & Item/extracted factor & 1 & 2 & 3 & 4 & 5 & 6 \\
\hline APFR & Warning others, who do not follow COVID-19 recommendations & 0.43 & & & & & 0.30 \\
\hline APFR & Wearing a mask while outside of my home & 0.39 & & & & & \\
\hline APFR & Washing my hands as frequently as possible & 0.42 & & & & & \\
\hline APFR & Violating recommendations for reducing the spread of COVID-19 & -0.40 & & & & & \\
\hline APFR & Limiting gatherings with high number of people & & & 0.31 & & & \\
\hline APFR & Disinfecting my personal stuff & 0.76 & & & & & \\
\hline APFR & Disinfecting the area around me & 0.84 & & & & & \\
\hline APFR & Spending time at home as much as possible & & & & & & \\
\hline APFR & Taking medicine to improve my immunity & 0.32 & & & & & \\
\hline APFR & Trying to listen to advice from others of how to protect myself & 0.30 & & & & & \\
\hline PS & Collecting supplies of food & & 0.78 & & & & \\
\hline PS & Collecting supplies of hygienic products & & 0.72 & & & & \\
\hline PS & Collecting supplies of medicine & & 0.80 & & & & \\
\hline REI & Using online platforms to connect with others & & & 0.30 & & 0.41 & \\
\hline REI & Trying to disperse my worries of COVID-19 by relaxing & & & 0.41 & & & \\
\hline REI & Looking for ways to overcome limitations caused by COVID-19 & & & 0.42 & & & \\
\hline REI & Looking for ways to please my relatives in a situation of limitations caused by COVID-19 & & & 0.38 & & & \\
\hline REI & Relaxing to improve my situation caused by COVID-19 & & & 0.70 & & & \\
\hline REI & Searching for art to improve my feelings caused by COVID-19 & & & 0.41 & & & \\
\hline NER & Arguing with others about themes connected with COVID-19 & & & & 0.43 & & \\
\hline NER & Angry about the COVID-19 situation & & & & 0.56 & & \\
\hline NER & Bored because of restrictions & & & & 0.47 & & \\
\hline NER & Feeling endangered by COVID-19 & & & & 0.47 & & \\
\hline SFI & Searching for COVID-19 information, not to miss anything important & & & & & 0.62 & \\
\hline SFI & Trying to share COVID-19 information with others & & & & & 0.40 & \\
\hline SFI & Studying medical information about protection from COVID-19 & & & & & 0.45 & \\
\hline HO & Spending time helping others restricted by COVID-19 situation & & & & & & 0.56 \\
\hline HO & Donating money or other resources to help others restricted by COVID-19 & & & & & & 0.39 \\
\hline HO & Taking over organization and management in situations that needed to be addressed because of COVID-19 & & & & & & 0.40 \\
\hline- & Praying or doing religious acts to protect myself and others from COVID-19 & & 0.31 & & & & \\
\hline - & Eating healthy to improve my immunity & & & 0.31 & & & \\
\hline- & Trying to reconcile with pandemic situation & & & & & & \\
\hline - & Working more than usual to avoid thinking about COVID-19 & & & & & & \\
\hline - & Trusting that government will deal with the situation & & & & & & \\
\hline- & Trying to reconcile with others, worrying that it would not be possible in the future & & & & & & 0.35 \\
\hline- & Searching for contact through online social networks & & & & & & \\
\hline \multicolumn{8}{|c|}{ Latent factor correlations } \\
\hline Factor 1 & & - & 0.49 & 0.50 & 0.10 & 0.45 & 0.35 \\
\hline Factor 2 & & & - & 0.35 & 0.30 & 0.48 & 0.32 \\
\hline Factor 3 & & & & - & 0.16 & 0.50 & 0.31 \\
\hline Factor 4 & & & & & - & 0.25 & 0.21 \\
\hline Factor 5 & & & & & & - & 0.24 \\
\hline
\end{tabular}

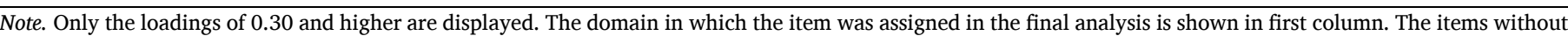

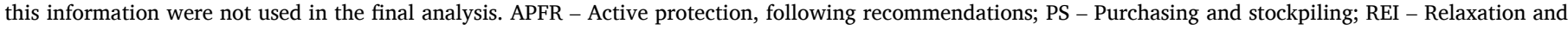
emotional improvement; NER - Negative emotional response; SFI - Search for information; HO - Helping others. 
Table B

Standardized factor loadings from CFA of the COVID-19 behavior scale.

\begin{tabular}{|c|c|c|c|c|c|c|}
\hline Item/domain & APFR & PS & REI & NER & SFI & HO \\
\hline Warning others, who do not follow COVID-19 recommendations & 0.63 & & & & & \\
\hline Wearing a mask while outside of my home & 0.66 & & & & & \\
\hline Washing my hands as frequently as possible & 0.64 & & & & & \\
\hline Violating recommendations for reducing the spread of COVID-19 & -0.26 & & & & & \\
\hline Limiting the gatherings with high number of people & 0.62 & & & & & \\
\hline Disinfecting my personal stuff & 0.68 & & & & & \\
\hline Disinfecting the area around me & 0.71 & & & & & \\
\hline Spending time at home as much as possible & 0.62 & & & & & \\
\hline Taking medicine to improve my immunity & 0.51 & & & & & \\
\hline Trying to listen to advice from others how to protect myself & 0.73 & & & & & \\
\hline Collecting supplies of food & & 0.82 & & & & \\
\hline Collecting supplies of hygienic products & & 0.85 & & & & \\
\hline Collecting supplies of medicine & & 0.83 & & & & \\
\hline Using online platforms to connect with others & & & 0.41 & & & \\
\hline Trying to disperse my worries of COVID-19 by relaxing & & & 0.69 & & & \\
\hline Looking for ways to overcome limitations caused by COVID-19 & & & 0.62 & & & \\
\hline Looking for ways to please my relatives in a situation of limitations caused by COVID-19 & & & 0.55 & & & \\
\hline Relaxing to improve my situation caused by COVID-19 & & & 0.61 & & & \\
\hline Searching for art to improve my feelings caused by COVID-19 & & & 0.65 & & & \\
\hline Arguing with others about issues connected with COVID-19 & & & & 0.50 & & \\
\hline Angry about the COVID-19 situation & & & & 0.22 & & \\
\hline Bored because of restrictions & & & & 0.36 & & \\
\hline Feeling in danger by COVID-19 & & & & 0.64 & & \\
\hline Searching for COVID-19 information, not to miss anything important & & & & & 0.75 & \\
\hline Trying to share COVID-19 information with others & & & & & 0.78 & \\
\hline Studying medical information about protection from COVID-19 & & & & & 0.80 & \\
\hline Spending time helping others restricted by COVID-19 situation & & & & & & 0.51 \\
\hline Donating money or other resources to help others restricted by COVID-19 & & & & & & 0.47 \\
\hline Taking over organization and management in situations that needed to be addressed because of COVID-19 & & & & & & 0.63 \\
\hline
\end{tabular}

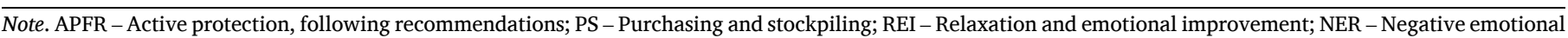

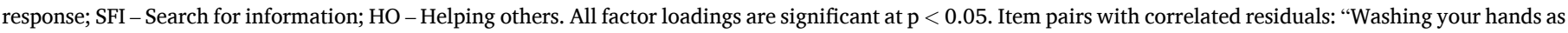

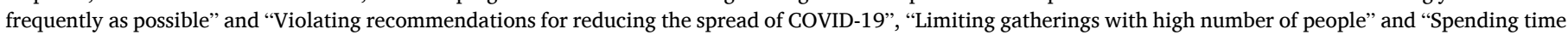

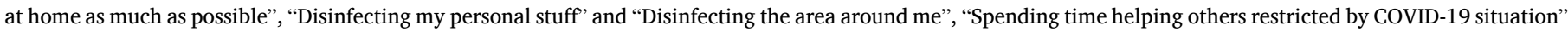
and "Donating money or other resources to help others restricted by COVID-19", "Angry about the COVID-19 situation" and "Bored because of restrictions".

Table C

Correlations between latent factors, COVID-19 domains, and internal consistency.

\begin{tabular}{|c|c|c|c|c|c|c|}
\hline Domain & APFR & PS & REI & NER & SFI & $\mathrm{HO}$ \\
\hline Active protection, following recommendations & $0.79 / 0.86$ & $0.43 / 0.61$ & $0.54 / 0.62$ & $0.23 / 0.24$ & $0.57 / 0.73$ & $0.27 / 0.49$ \\
\hline Purchasing and stockpiling & 0.70 & $0.81 / 0.87$ & $0.24 / 0.53$ & $0.27 / 0.40$ & $0.41 / 0.59$ & $0.21 / 0.48$ \\
\hline Relaxation and emotional improvement & 0.76 & 0.64 & $0.69 / 0.76$ & $0.25 / 0.34$ & $0.49 / 0.60$ & $0.27 / 0.49$ \\
\hline Negative emotional response & 0.61 & 0.70 & 0.64 & $0.63 / 0.56$ & $0.38 / 0.35$ & $0.06 / 0.32$ \\
\hline Search for information & 0.89 & 0.70 & 0.76 & 0.73 & $0.71 / 0.82$ & $0.27 / 0.50$ \\
\hline Helping others & 0.76 & 0.73 & 0.75 & 0.80 & 0.78 & $0.50 / 0.63$ \\
\hline
\end{tabular}

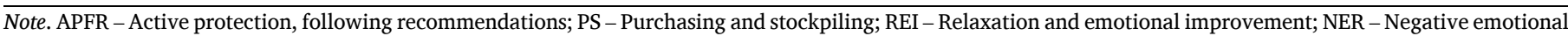

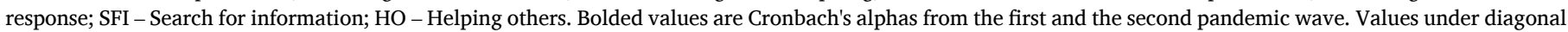

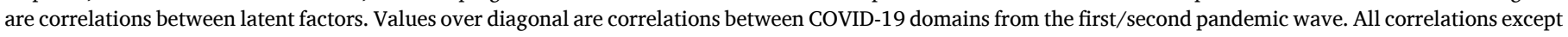
one (italicized) are significant at $\mathrm{p}<0.05$.

Table D

Gender differences and correlations for variables used in hierarchical linear regression analyses.

\begin{tabular}{|c|c|c|c|c|c|c|c|}
\hline & Gender & Age & Extraversion & Agreeableness & Conscientiousness & Negative emotionality & Open-mindedness \\
\hline Age & -0.26 & - & - & - & - & - & - \\
\hline T1 APFR & -0.57 & 0.05 & 0.12 & 0.21 & 0.18 & 0.01 & 0.13 \\
\hline T2 APFR & -0.48 & 0.12 & 0.02 & 0.13 & 0.14 & 0.06 & 0.11 \\
\hline T1-T2 APFR & 0.06 & -0.11 & 0.09 & 0.03 & 0.00 & -0.07 & -0.01 \\
\hline T1 PS & -0.33 & -0.02 & 0.10 & 0.02 & 0.10 & 0.14 & -0.06 \\
\hline T2 PS & -0.46 & 0.03 & -0.02 & -0.01 & 0.04 & 0.19 & -0.07 \\
\hline T1-T2 PS & 0.15 & -0.06 & 0.14 & 0.03 & 0.07 & -0.07 & 0.00 \\
\hline T1 REI & -0.42 & 0.08 & 0.15 & 0.23 & 0.05 & -0.02 & 0.29 \\
\hline T2 REI & -0.33 & 0.17 & 0.08 & 0.12 & 0.02 & 0.07 & 0.24 \\
\hline T1-T2 REI & -0.04 & -0.10 & 0.07 & 0.10 & 0.02 & -0.10 & 0.02 \\
\hline T1 NER & -0.11 & -0.04 & -0.10 & -0.21 & -0.23 & 0.40 & -0.14 \\
\hline T2 NER & -0.17 & 0.07 & -0.13 & -0.22 & -0.17 & 0.36 & -0.11 \\
\hline T1-T2 NER & 0.05 & -0.11 & 0.02 & -0.02 & -0.08 & 0.08 & -0.04 \\
\hline T1 SFI & -0.13 & 0.02 & 0.04 & 0.12 & 0.12 & 0.08 & 0.13 \\
\hline T2 SFI & -0.22 & 0.10 & -0.06 & 0.08 & 0.10 & 0.10 & 0.07 \\
\hline
\end{tabular}


Table D (continued)

\begin{tabular}{|c|c|c|c|c|c|c|c|}
\hline & Gender & Age & Extraversion & Agreeableness & Conscientiousness & Negative emotionality & Open-mindedness \\
\hline T1-T2 SFI & 0.11 & -0.09 & 0.10 & 0.03 & 0.01 & -0.04 & 0.05 \\
\hline T1 HO & -0.27 & -0.06 & 0.20 & 0.24 & 0.18 & -0.08 & 0.17 \\
\hline $\mathrm{T} 2 \mathrm{HO}$ & -0.13 & 0.06 & 0.12 & 0.07 & 0.07 & 0.02 & 0.18 \\
\hline T1-T2 HO & -0.12 & -0.11 & 0.07 & 0.16 & 0.10 & -0.09 & 0.00 \\
\hline Extraversion & 0.04 & 0.06 & - & - & - & - & - \\
\hline Agreeableness & -0.57 & 0.19 & 0.321 & - & - & - & - \\
\hline Conscientiousness & -0.19 & 0.07 & 0.379 & 0.402 & - & - & - \\
\hline Negative emotionality & -0.35 & -0.10 & -0.501 & -0.418 & -0.397 & - & - \\
\hline Open-mindedness & 0.00 & 0.08 & 0.501 & 0.375 & 0.429 & -0.296 & - \\
\hline
\end{tabular}

Note. Gender - Cohen's d, negative number indicate higher value for women. T1 - first COVID-19 pandemic wave; T2 - second COVID-19 pandemic wave; T1-T2 difference between two pandemic waves. APFR - Active protection, following recommendations; PS - Purchasing and stockpiling; REI - Relaxation and emotional improvement; NER - Negative emotional response; SFI - Search for information; HO - Helping others. Bolded values are significant at $\mathrm{p}<0.05$.

\section{References}

Ahorsu, D. K., Lin, C. Y., Imani, V., Saffari, M., Griffiths, M. D., \& Pakpour, A. H. (2020). The fear of COVID-19 scale: Development and initial validation. International Journal of Mental Health and Addiction, 1-9. Advance online publication https://doi. org/10.1007/s11469-020-00270-8.

Ako sa máte, Slovensko. (2020). Pandémiou sa cítime rovnako ohrození ako v marci. [We feel as threatened by the pandemic as in March.]. http://www.sociologia.sav.sk /cms/uploaded/3153_attach_ASMS_november_obavy.pdf.

Badgaiyan, A. J., \& Verma, A. (2015). Does urge to buy impulsively differ from impulsive buying behavior? Assessing the impact of situational factors. Journal of Retailing and Consumer Services, 22, 145-157. https://doi.org/10.1016/j.jretconser.2014.10.002.

Bedford-Petersen, C., \& Saucier, G. (2021). Identifying contrasting themes that orchestrate personality expression across situations. Personality and Individual Differences, 171, 110495. https://doi.org/10.1016/j.paid.2020.110495.

Bentzen, J. S. (2019). Acts of god? Religiosity and natural disasters across subnational world districts. The Economic Journal, 129(622), 2295-2321. https://doi.org/ 10.1093/ej/uez008.

Blagov, P. S. (2020). Adaptive and dark personality in the COVID-19 pandemic: Predicting health-behavior endorsement and the appeal of public-health messages. Social Psychological and Personality Science. https://doi.org/10.1177/ 1948550620936439. Advance online publication.

Bogg, T., \& Milad, E. (2020). Demographic, personality, and social cognition correlates of coronavirus guideline adherence in U.S. sample. Health Psychology., 39(12), 1026-1036. https://doi.org/10.1037/hea0000891.

Brooks, S. K., Webster, R. K., Smith, L. E., Woodland, L., Wessely, S., Greenberg, N., \& Rubin, G. J. (2020). The psychological impact of quarantine and how to reduce it: Rapid review of the evidence. Lancet, 395, 912-920. https://doi.org/10.1016/ s0140-6736(20)30460-8.

Caci, B., Miceli, S., Scrima, F., \& Cardaci, M. (2020). Neuroticism and fear of COVID-19. The interplay between boredom, fantasy engagement, and perceived control over time. Frontiers in Psychology, 11, 574393. https://doi.org/10.3389/ fpsyg. 2020.574393.

Cao, S., \& Xia, L. X. (2020). Conscientiousness mediates the link between brain structure and consideration of future consequence. Neuropsychologia, 141, 107435. https:// doi.org/10.1016/j.neuropsychologia.2020.107435.

Carvalho, L. F., Pianowski, G., \& Gonçalves, A. P. (2020). Personality differences and COVID-19: Are extraversion and conscientiousness personality traits associated with engagement with containment measures? Trends in Psychiatry and Psychotherapy, 42 (2), 179-184. https://doi.org/10.1590/2237-6089-2020-0029.

Chan, H. F., Moon, J. W., Savage, D. A., Skali, A., Torgler, B., \& Whyte, S. (2020). Can psychological traits explain mobility behavior during the COVID-19 pandemic? Social Psychological and Personality Science. https://doi.org/10.1177/ 1948550620952572. Advance online publication.

Daly, M., \& Robinson, E. (2020). Psychological distress and adaptation to the COVID-19 crisis in the United States. Journal of Psychiatric Research, 136, 603-609. https://doi. org/10.1016/j.jpsychires.2020.10.035.

Dammeyer, J. (2020). An explorative study of the individual differences associated with consumer stockpiling during the early stages of the 2020 coronavirus outbreak in Europe. Personality and Individual Differences, 167, 110263. https://doi.org/ 10.1016/j.paid.2020.110263.

Diefendorff, J. M., Richard, E. M., \& Yang, J. (2008). Linking emotion regulation strategies to affective events and negative emotions at work. Journal of Vocational Behavior, 73(3), 498-508. https://doi.org/10.1016/j.jvb.2008.09.006.

Duncan, L. A., Schaller, M., \& Park, J. H. (2009). Perceived vulnerability to disease: Development and validation of a 15-item self-report instrument. Personality and Individual Differences, 47(6), 541-546. https://doi.org/10.1016/j.paid.2009.05.001.

Garbe, L., Rau, R., \& Toppe, T. (2020). Influence of perceived threat of COVID-19 and HEXACO personality traits on toilet paper stockpiling. PLoS One, 15(6), Article e0234232. https://doi.org/10.1371/journal.pone.0234232.
Habashi, M. M., Graziano, W. G., \& Hoover, A. E. (2016). Searching for the prosocial personality: A Big Five approach to linking personality and prosocial behavior. Personality and Social Psychology Bulletin, 42(9), 1177-1192. https://doi.org/ 10.1177/0146167216652859.

Halama, P., Kohút, M., Soto, C. J. \& John, O. (2020). Slovak adaptation of the big five inventory (BFI-2): Psychometric properties and initial validation. Studia Psychologica, 62(1), 74-87. Doi:10.31577/sp.2020.01.792.

Infurna, F. J., \& Luthar, S. S. (2018). Re-evaluating the notion that resilience is commonplace: A review and distillation of directions for future research, practice, and policy. Clinical Psychology Review, 65, 43-56. https://doi.org/10.1016/j. cpr.2018.07.003.

Jang, K., \& Baek, Y. M. (2019). When information from public health officials is untrustworthy: The use of online news, interpersonal networks, and social media during the MERS outbreak in South Korea. Health Communication, 34(9), 991-998. https://doi.org/10.1080/10410236.2018.1449552.

Kline, R., Bankert, A., Levitan, L., \& Kraft, P. (2019). Personality and prosocial behavior: A multi-level meta-analysis. Political Science Research and Methods, 7(1), 125-142. https://doi.org/10.1017/psrm.2017.14.

Kohút, M., Kohútová, V., Žitný, P. \& Halama, P. (2020). Further validation of Slovak Big Five Inventory 2: 6-months test-retest stability and predictive power. Studia Psychologica, 62(3), 246-258. Doi:10.31577/sp.2020.03.803.

Kroencke, L., Geuker, K., Utesch, T., Kuper, N., \& Back, M. D. (2020). Neuroticism and emotional risk during the COVID-19 pandemic. Journal of Research in Personality, 89, 104038. https://doi.org/10.1016/j.jrp.2020.104038.

Levkovich, I., \& Shinan-Altman, S. (2020). Impact of the COVID-19 pandemic on stress and emotional reactions in Israel: A mixed-methods study. International Health. https://doi.org/10.1093/inthealth/ihaa081. Advance acess.

Mooradian, T. A., \& Swan, K. S. (2006). Personality-and-culture: The case of national extraversion and word-of-mouth. Journal of Business Research, 59(6), 778-785. https://doi.org/10.1016/j.jbusres.2006.01.015.

Oosterhoff, B., Shook, N. J., \& Iyer, R. (2018). Disease avoidance and personality: A meta-analyses. Journal of Research in Personality, 77, 47-56. https://doi.org/ 10.1016/j.jrp.2018.09.008.

Sadiković, S., Branovački, B., Oljača, M., Mitrović, D., Pajić, D., \& Smederevac, S. (2020). Daily monitoring of emotional responses to the coronavirus pandemic in Serbia: A citizen science approach. Frontiers in Psychology, 19(11), 2133. https://doi.org/ 10.3389/fpsyg.2020.02133.

Schaller, M. (2006). Parasites, behavioral defenses, and the social psychological mechanisms through which cultures ere evoked. Psychological Inquiry, 17(2). https:// doi.org/10.1207/s15327965pli1702_2, 96-37.

Shook, N., Sevi, B., Lee, J., Ooosterhoff, B., \& Fitzgerald, H. N. (2020). Disease avoidance in the time of COVID-19: The behavioral immune system is associated with concern and preventative health behaviors. PLoS One, 15(8), Article e0238015. https://doi. org/10.1371/journal.pone.0238015.

Smith, B. W., Kay, V. S., Hoyt, T. V., \& Bernard, M. L. (2009). Predicting the anticipated emotional and behavioral responses to an avian flu outbreak. American Journal of Infection Control, 37(5), 371-380. https://doi.org/10.1016/j.ajic.2008.08.007.

Soto, C. J., \& John, O. (2017). The next Big Five Inventory (BFI-2): Developing and assessing a hierarchical model with 15 facets to enhance bandwidth, fidelity, and predictive power. Journal of Personality and Social Psychology, 113(1), 117-143. https://doi.org/10.1037/pspp0000096.

Šrol, J., Ballová-Mikušková, E., \& Čavojová, V. (2021). When we are worried, what are we thinking? Anxiety, lack of control, and conspiracy beliefs amidst the COVID-19 pandemic. Applied Cognitive Psychology. https://doi.org/10.1002/acp.3798. Early view.

Zajenkowski, M., Jonason, P. K., Leniarska, M., \& Kozakiewicz, Z. (2020). Who complies with the restrictions to reduce the spread of COVID-19?: Personality and perceptions of the COVID-19 situation. Personality and Individual Differences, 166, 110199. https://doi.org/10.1016/j.paid.2020.110199. 